\title{
Design of Contact and Non-Contact Tachometer Using Microcontroller
}

\author{
Tatiya Padang Tunggal ${ }^{1}$, Lailicia Anggi Kirana ${ }^{2}$, Afif Zuhri Arfianto ${ }^{3}$, Elsayed T. Helmy ${ }^{4}$, Farhad Waseel ${ }^{5}$ \\ 1,2 Department of Electrical Engineering, Universitas Muhammadiyah Yogyakarta, Yogyakarta, Indonesia \\ ${ }^{3}$ Program Studi Teknik Otomasi, Jurusan Kelistrikan Kapal, Politeknik Perkapalan Negeri Surabaya \\ ${ }^{4}$ National Institute of oceanography and fisheries, Alexandria, Egypt \\ ${ }^{5}$ Department of mathematics, Kabul University, Kabul, Afghanistan \\ tatiyapt@umy.ac.id, lailicia_anggi_kirana@umy.ac.id, afifzuhri@ieee.org, stalaat41@gmail.com, \\ Farhadwaseel@ku.edu.af
}

\begin{abstract}
Calibration is required for various kinds of tools from kitchen tools such as stirrers or mixers to medical tools such as temperature calibration, ECG, blood pressure, and other instrumentation tools to be according to the required standards. In medical devices, a digital tachometer has been used as a calibration support device to measure the speed of objects that rotate in RPM on the centrifuge. Some medical devices are calibrated in $\mathbf{k m} / \mathbf{h o u r}$, for example, the ergo cycle and treadmill. Two different devices or a conversion from RPM to $\mathrm{km} / \mathrm{hour}$ are required. The research aimed to design a measurement device that performed calibration of devices with different units, namely tachometer that can be used to measure speed in RPM and $\mathrm{km} / \mathrm{hr}$. Based on the research objective, a tool was made to measure the motor's rotational speed using the E18-D80NK sensor, microcontroller, and LCD without touching the object being measured.
\end{abstract}

Keywords - tachometer, rotation per minute, microcontroller

\section{INTRODUCTION}

Every medical device used in health service facilities and other health facilities must be tested or calibrated regularly by the Health Facilities Testing Institute. Testing, in this term, is an overall measure that includes physical examination and measurement to compare the measuring instrument with the standard, or to determine the magnitude error or measurement error. Calibration is an activity to determine the correctness of the value of the measuring instruments and measuring materials. Test and calibration results are written statements stating whether the medical device is suitable for use or not based on the test and calibration results. The arrangement of testing and calibration of medical devices aims to guarantee that the medical devices are following the service standards, quality requirements, safety, benefits, and usability in health care facilities or other health facilities. Some medical devices, such as centrifuges and treadmills, need to be calibrated. One of the devices used for calibration is a tachometer.

A tachometer is a measuring instrument made and designed to measure the speed of rotating objects. The procedure of a tachometer is shooting infrared light at the plane reflective, which will reflect infrared light received by a detector. Some researchers have researched motor rotational speed measures such as Plante and Lane who investigated error detection and failure prediction using vibration analysis and current motor signature analysis to detect imbalanced motor resistance, respectively. The motor condition monitoring experiment was regulated, and the operational speed of the motor was controlled by the AC motor drive [1]. The increased motor stator resistance affected the performance, efficiency, and voltage/current characteristics during the operation of the latest generation of unmodified AC PWM drives under various speed conditions [2]. Zhang studied the uncensored speed estimate of the feedinduction motor for monitoring conditions using motor relays. An accurate speed estimation technique was proposed for power supply induction motors [3]. Rane researched Web-based DC motor monitoring and control using the LabVIEW environment. By using a full-wave converter based on thyristors, DC motor speed control can be done by varying the pulse burning angle given to the thyristor [4]. Monadi examined the estimated speed of a damaged threephase induction motor using the adaptive reference model system. A method for estimating the speed of a damaged three-phase induction motor (three-phase induction motor under an open-phase winding stator) based on the Model Reference Adaptive System (MRAS) was presented [5].

Strankowski studied sensorless induction motor error detection with an inverter output filter. He investigated the problem of monitoring and fault detection of a sensorless voltage inverter fed squirrel cage induction motor with an LC filter [6]. Ferreira used a webcam-based tachometer for estimating induction motor loads in the field. The rotational speed measurement was a major problem in most industries for process control, characterization, or fault diagnosis [7]. Angalaeswari examined the speed control of permanent magnet DC (PM) motors using Arduino and LabVIEW. The speed control of a DC Permanent Magnet motor (PMDC) was performed using the VIEW Lab connected to Arduino [8]. The shear-mode and fuzzy-logic adaptation mechanism for sensorless MRAS Controlled Vector Induction Motor with temperature monitoring was investigated by Lipina Gopal M. Various methods are proposed for the estimation of speed on sensorless induction motor drives [9]. Alonazi studied current 
motor waveform simulation in monitoring the state of the aortic valve during ventricular support. The data would be useful in the development of pump speed controllers for optimal management of pump outputs [10].

The operating state analysis on an asynchronous motor with a stator slot frequency vibration, studied by Biernat 800 $\mathrm{kW}$, used vertical low-speed rotational speed of an asynchronous motor coupled with a diagonal pump characterizing a qualitative change in housing vibration that depends on slight changes in load and voltage in the mounting of the motor frame [11]. The design of an induction motor efficiency monitoring system without using a torque meter and speed sensor was investigated by Mamizadeh that accurately measured efficiency by including all losses without using a torque meter and speed sensor [12]. Different measurement techniques for detecting bearing errors on industrial actuators - a comparative study researched by Partners - operated via Variable Frequency Drive (VFD) in high power actuators used in industrial process control operations which were very challenging due to dynamic changes of load, speed, and external interference [13]. The electrical monitoring of mechanical damage to the V-beltpulley speed reduction clutch driven by an induction motor was investigated by Kang, typically used for speed reduction in industrial applications driven by induction motors because of flexible power transmission at a low cost [14]. Induction motor condition monitoring, Vibration analysis technique diagnosis of electromagnetic anomalies was investigated by Tsypkin. The industry currently has used many types of nonlinear systems that operate in power lines, for example, adjustable speed drives, which cause voltage distortion in induction motor supplies and power lines [15].

Khan-Ngern investigated High-Performance BLDC Motor Control for Electric Vehicles. The EDs helped adjust wheel speed when cornering by driving two BLDC motors mounted on two rear wheels [16]. The development of a lowcost brushless DC motor sensorless controller using dsPIC30F4011 investigated by Karnavas using sensorless techniques avoiding to use Hall sensors [17]. Bearing Error Detection Classification Using SVM Multiclass was studied by Zgarni, like a drive speed that was set for bearing fault detection [18]. Sboui studied and observed the behavior of Network-Connected Induction Generators Experiencing Low-Frequency Ripple Speed with Driving Speed, and the effect of low-frequency ripple of drive speed on the quality of the injected current and the instantaneous power debited by an induction generator into the connection network [19]. Sensorless Speed Control Based on Back-EMF from the Four Switch BLDC Motor Drive was investigated by Reshma using a new technique introduced to control the drive speed of a Brushless DC Four-motor (FSBLDC) motor, by feeling the back-emf developed through the stator winding [20].

Based on the literature review, several researchers have investigated motor speed measures using rotary encoder sensors, optical sensors, magnetic sensors, and current sensors. The paper explains the measurement of motor rotation speed, differing from previous studies, that is the measurement of motor rotation speed using non-contact technology.

\section{METHODS}

A block diagram is made to map the process of work. It facilitates someone to understand how a system works. Figure 1 displays the system block diagram. It consists of Sensor E18-D80NK, setting mode, stored data, a microcontroller [8], [21]-[23], and an LCD.

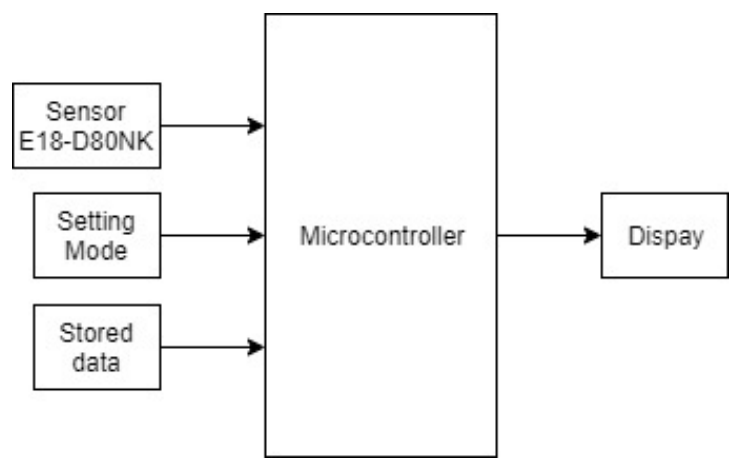

Fig. 1. System block diagram

\section{A. System workflow program}

A flowchart displayed in Figure 2 is a diagram with graphical symbols that expresses the flow of an algorithm or a process that displays the steps symbolized in the form of a box by connecting each of the steps using an arrow.

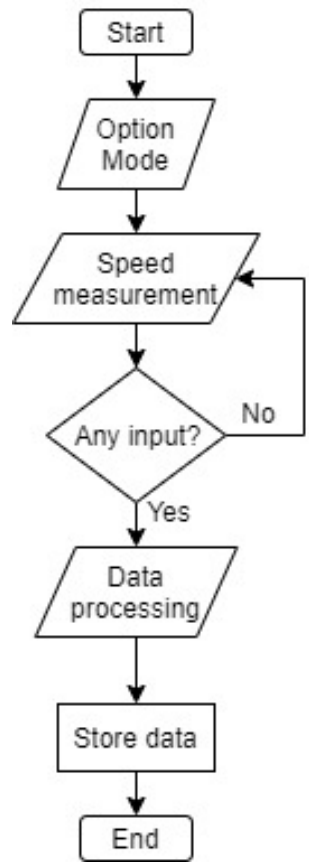

Fig. 2. System workflow diagram

The measurement unit setting is in the form of contact (km/hour) or non-contact (RPM). The start button worked to start the measurement. The infrared transmitter emitted waves fired at an object. The object was given a white line as a reflective plane, which would be captured by the 
phototransistor as a receiver. The receiver output would be forwarded and converted in RPM or $\mathrm{km} / \mathrm{hour}$ by the microcontroller [24]-[28], and the results would be displayed on a $16 \times 2$ LCD.

The users set the mode selection in RPM or $\mathrm{km} /$ hour before measuring it. Pressing the start button would start the measurement [29], [30], and it would stop automatically within one minute. The data would be automatically stored in the device every six seconds.

\section{B. System hardware}

The system's minimum circuit block functions as the brain of the device containing the commands and conditions of the sensor or other blocks programmed in this circuit block in show Figure 3. LCD circuit functions to connect the minimum system circuit with the LCD, which is useful for displaying commands that are running.

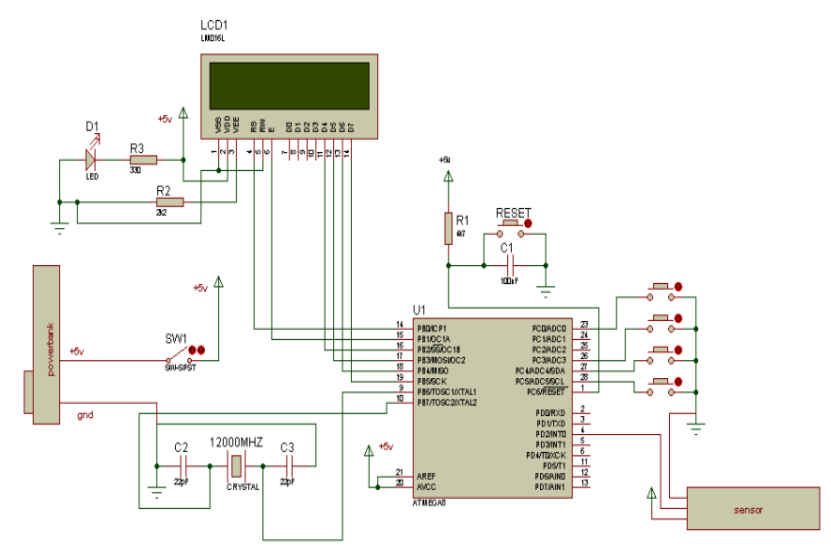

Fig. 3. Minimum system schematic

The transmitter circuit on the E 18-D 80NK sensor is when the power is pressed then the infrared will radiate to the reflector of the rotating object. Then enter the regulator rectifier to stabilize the voltage. After the voltage is stable, enter the modulator. The modulator is a circuit that functions to superimpose data on the carrier wave frequency to a signal so that it can be sent to the receiver via certain media such as cable or air.

The system's minimum circuit block functions as the brain of the device containing the commands and conditions of the sensor or other blocks programmed in this circuit block in show figure 3. LCD circuit functions to connect the minimum system circuit with the LCD, which is useful for displaying commands that are running.

The transmitter circuit on the E 18-D 80NK sensor is when the power is pressed then the infrared will radiate to the reflector of the rotating object. Then enter the regulator rectifier to stabilize the voltage. After the voltage is stable, enter the modulator. A modulator is a circuit that functions to superimpose data on the carrier wave frequency to a signal so that it can be sent to the receiver via certain media such as cable or air.
In the receiver circuit, a phototransistor received an infrared light emitted/reflected on the reflector, and then the light was converted to voltage and amplified by an amplifier. The voltage entered the demodulator after it was strengthened. A demodulator was the process of reading/separating data from the received signal. The output of the demodulator affirmed that the clock logic was readable on the microcontroller, and later entered the microcontroller via the PD2/INT0 counter. The counter helped to calculate the clock derived from the sensor, which was then processed to calculate the value of RPM or $\mathrm{km} /$ hour.

\section{Measurement variables}

1). Independent Variable

The independent variable was the motor rotation speed, as the motor rotation was not affected by the circuit on the calibration device

\section{2). Dependent Variable}

The dependent variable was the infrared sensor E 18-D 80NK because the study uses those sensors.

\section{3). Controllable Variable}

The controlled variable was the AT Mega microcontroller IC worked as a data processor.

\section{RESULT AND DISCUSSION}

\section{A. Testing Techniques with RPM Unit}

The test on RPM speed readings on the centrifuge was carried out at speeds of 360 RPM, 960 RPM, 1440 RPM, 1740 RPM, 2100 RPM, 3600 RPM, 5400 RPM, and 7300 RPM. The result is shown in Table I.

TABLE I. Overall SPEEd RPM MEASUREMENT RESUlt

\begin{tabular}{|c|c|c|c|c|}
\hline No & RPM & $\begin{array}{c}\text { Device's } \\
\text { average } \\
\text { speed }\end{array}$ & $\begin{array}{c}\text { Absolute } \\
\text { error }\end{array}$ & $\begin{array}{c}\text { Error } \\
\text { percentage }\end{array}$ \\
\hline 1 & 360 & 359.55 & 0.75 & $0.20 \%$ \\
\hline 2 & 960 & 958.7 & 2.7 & $0.28 \%$ \\
\hline 3 & 1440 & 1438.2 & 2.95 & $0.20 \%$ \\
\hline 4 & 1740 & 1736.7 & 6.55 & $0.37 \%$ \\
\hline 5 & 2100 & 2114.5 & 3.8 & $0.17 \%$ \\
\hline 6 & 3600 & 3596.25 & 6.15 & $0.17 \%$ \\
\hline 7 & 5400 & 5394.8 & 6.5 & $0.12 \%$ \\
\hline 8 & 7300 & 7296.45 & 6.8 & $0.09 \%$ \\
\hline
\end{tabular}

Based on the measurement and testing of devices at RPM speed, the smallest absolute error value was 0.75 at 360 RPM speed, and the largest absolute error value was 6.8 at 7300 RPM speed. The smallest percentage of error was $0.09 \%$ at 7300 RPM, and the largest percentage of errors was $0.37 \%$ at 1740 RPM. Based on the test results, the device experienced the smallest accuracy at a speed of 360 RPM with an absolute 
error value of 0.75 and the highest accuracy at a speed of 3600 RPM with an absolute error value of 6.15. Table 1 presents the overall speed RPM measurement results.

\section{B. Testing Techniques with $\mathrm{km} / \mathrm{hour}$ Unit}

Testing the speed reading of $\mathrm{km} / \mathrm{hour}$ on a treadmill was carried out at speeds of $2.2 \mathrm{~km} /$ hour, $3.4 \mathrm{~km} / \mathrm{hour}, 4.9$ $\mathrm{km} /$ hour, $7 \mathrm{~km} /$ hour. The measurement error is shown in Table II.

TABLE II. THE MEASUREMENT ERROR

\begin{tabular}{|c|c|c|c|c|}
\hline No & Km/hour & $\begin{array}{c}\text { Device's } \\
\text { average speed }\end{array}$ & Absolute error & $\begin{array}{c}\text { Error } \\
\text { percentage }\end{array}$ \\
\hline 1 & 2.2 & 2.1 & 0.1 & $4.50 \%$ \\
\hline 2 & 3.4 & 3.4 & 0 & 0 \\
\hline 3 & 4,9 & 4.8 & 0,1 & $2.04 \%$ \\
\hline 4 & 7 & 6.8 & 0.2 & $2.85 \%$ \\
\hline
\end{tabular}

Based on the measurement and testing of devices at $\mathrm{km} / \mathrm{h}$ speed in Table II, the smallest absolute error value was 0 at $3.4 \mathrm{~km} /$ hour speed, and the largest absolute error value of 0.2 at $7 \mathrm{~km} /$ hour speed. The smallest percentage of error was 0 at a speed of $3.4 \mathrm{~km} /$ hour, and the largest percentage of errors was $4.5 \%$ at a speed of $2.2 \mathrm{~km} /$ hour. Based on the test results, the device experienced the smallest accuracy at a speed of 3.4 $\mathrm{km} / \mathrm{h}$ with an absolute error value of 0 and the highest accuracy at a speed of $7 \mathrm{~km} / \mathrm{h}$ with an absolute error value of 0.2. Table 2 presents the overall speed ( $\mathrm{km} / \mathrm{hour}$ ) measurement results.

\section{CONCLUSIONS}

Based on the testing and data retrieval at speeds of 360 RPM, 960 RPM, 1440 RPM, 1740 RPM, 2100 RPM, 3600 RPM, 5400 RPM, and 7300 RPM, the smallest accuracy obtained is at 360 RPM with absolute error values of 0.75 , and the highest accuracy is at 3600 RPM with an absolute error of 6.15. The performance of the device is most desirable at low to medium speeds, and it starts to decline at high speeds. The lowest accuracy achieved is $3.4 \mathrm{~km} / \mathrm{h}$ with an absolute error value of 0 , depending on the testing and data retrieval taken from the speeds of $2.2 \mathrm{~km} / \mathrm{h}, 3.4 \mathrm{~km} / \mathrm{h}, 4.9$ $\mathrm{km} / \mathrm{h}$, and $7 \mathrm{~km} / \mathrm{h}$, and the greatest accuracy is $7 \mathrm{~km} / \mathrm{h}$ with an absolute error of 0.2. The device performance is best at low to medium speeds, and it starts to decline at high speeds.

\section{REFERENCES}

[1] T. Plante, A. Nejadpak, and C. Xia Yang, "Faults detection and failures prediction using vibration analysis," in 2015 IEEE AUTOTESTCON, 2015, vol. 2015-Decem, pp. 227-231.

[2] M. Lane, D. Ashari, F. Gu, and A. D. Ball, "Investigation of motor current signature analysis to detect motor resistance imbalances," in 2015 21st International Conference on Automation and Computing (ICAC), 2015, pp. 1-4.

[3] P. Zhang, P. Neti, and S. Grubic, "Sensorless speed estimation of mains-fed induction motors for condition monitoring using motor relays," in 2015 IEEE Energy Conversion Congress and Exposition (ECCE), 2015, pp. 2840-2845.
[4] H. K. Rane and S. K. Parchandekar, "A web-based monitoring and control of DC motor using LabVIEW environment," in 2015 International Conference on Smart Technologies and Management for Computing, Communication, Controls, Energy and Materials (ICSTM), 2015, no. May, pp. 543-547.

[5] A. Monadi, M. Jannati, N. R. . Idris, and S. E. Alavi, "Speed estimation of faulty three-phase induction motor using model reference adaptive system," in 2015 IEEE Conference on Energy Conversion (CENCON), 2015, pp. 368-372.

[6] P. Strankowski and J. Guzinski, "Sensorless fault detection of induction motor with inverter output filter," in 2016 Progress in Applied Electrical Engineering (PAEE), 2016, pp. 1-6.

[7] F. J. T. E. Ferreira and F. J. P. Lopes, "Webcam-based tachometer for in-field induction motor load estimation," in 2016 XXII International Conference on Electrical Machines (ICEM), 2016, pp. 2380-2388.

[8] S. Angalaeswari, A. Kumar, D. Kumar, and S. Bhadoriya, "Speed control of permanent magnet (PM)DC motor using Arduino and LabVIEW," in 2016 IEEE International Conference on Computational Intelligence and Computing Research (ICCIC), 2016, pp. 1-6.

[9] Lipina Gopal M. and T. George, "Sliding-mode and fuzzy-logic adaptation mechanism for MRAS sensorless Vector Controlled Induction Motor with temperature monitoring," in 2016 Conference on Emerging Devices and Smart Systems (ICEDSS), 2016, pp. 117124.

[10] K. A. Alonazi, N. H. Lovell, and S. Dokos, "Simulation of motor current waveforms in monitoring aortic valve state during ventricular assist device support," in 2016 38th Annual International Conference of the IEEE Engineering in Medicine and Biology Society (EMBC), 2016, vol. 2016-Octob, pp. 1451-1454.

[11] A. Biernat and P. Goralski, "Analysis of state of operation of asynchronous motor with stator slot frequency beat vibration," in 2017 International Symposium on Electrical Machines (SME), 2017, pp. 1-4.

[12] A. Mamizadeh and I. Iskender, "Designing of induction motor efficiency monitoring system without using torque meter and speed sensor," in 2017 International Conference on Optimization of Electrical and Electronic Equipment (OPTIM) \& 2017 Intl Aegean Conference on Electrical Machines and Power Electronics (ACEMP), 2017, pp. 330-335.

[13] S. Mitra and C. Koley, "Different measurement techniques for detection of bearing faults in industrial actuators - comparative study," in 2017 IEEE Calcutta Conference (CALCON), 2017, vol. 2018-Janua, pp. 412-417.

[14] T.-J. Kang, C. Yang, Y. Park, S. Bin Lee, and M. Teska, "Electrical monitoring of mechanical defects in induction motor driven V-beltpulley speed reduction couplings," in 2017 IEEE Energy Conversion Congress and Exposition (ECCE), 2017, vol. 54, no. 3, pp. 293-300.

[15] M. Tsypkin, "Induction motor condition monitoring: Vibration analysis technique - diagnosis of electromagnetic anomalies," in 2017 IEEE AUTOTESTCON, 2017, pp. 1-7.

[16] W. Khan-Ngern, W. Keyoonwong, N. Chatsiriwech, P. Sangnopparat, P. Mattayaboon, and P. Worawalai, "High Performance BLDC Motor Control for Electric Vehicle," in 2018 International Conference on Engineering, Applied Sciences, and Technology (ICEAST), 2018, pp. 1-4.

[17] Y. L. Karnavas, A. S. Topalidis, and M. Drakaki, "Development of a low cost brushless DC motor sensorless controller using dsPIC30F4011," in 2018 7th International Conference on Modern Circuits and Systems Technologies (MOCAST), 2018, pp. 1-4.

[18] S. Zgarni and A. Braham, "Classification of Bearing Fault Detection Using Multiclass SVM: A Comparative Study," in 2018 15th International Multi-Conference on Systems, Signals \& Devices (SSD), 2018, pp. 888-892.

[19] A. Sboui, M. Salah, A. El Fahem, K. Bacha, A. Chaari, and M. Gharbi, "Behavior of a Grid-Connected Induction-Generator Subjected to a Driving-Speed Low-Frequency Ripples," in 2018 
15th International Multi-Conference on Systems, Signals \& Devices (SSD), 2018, pp. 876-881.

[20] K. M. Reshma and T. B. Isha, "A Back-EMF Based Sensorless Speed Control of Four Switch BLDC Motor Drive," in 2018 International Conference on Control, Power, Communication and Computing Technologies (ICCPCCT), 2018, no. 1, pp. 283-287.

[21] I. Anshory, I. Robandi, and Wirawan, "Monitoring and optimization of speed settings for Brushless Direct Current (BLDC) using Particle Swarm Optimization (PSO)," in 2016 IEEE Region 10 Symposium (TENSYMP), 2016, pp. 243-248.

[22] G. Pavithra and V. V. Rao, "Remote Monitoring and Control of VFD fed Three Phase Induction Motor with PLC and LabVIEW software," in 2018 2nd International Conference on I-SMAC (IoT in Social, Mobile, Analytics and Cloud) (I-SMAC) I-SMAC (IoT in Social, Mobile, Analytics and Cloud) (I-SMAC), 2018 2nd International Conference on, 2018, pp. 329-335.

[23] S. Yadav, A. Pohekar, and K. Surender, "Performance Monitoring System for driver with light motor vehicle (LMV) learner's license," in 2016 International Conference on Computing Communication Control and automation (ICCUBEA), 2016, no. Lmv, pp. 1-6.

[24] V. I. Smolin, I. G. Topolskaya, and G. I. Volovich, "The energy method for monitoring the instantaneous state and the formation of a synchronous motor control variables," in 2016 2nd International Conference on Industrial Engineering, Applications and Manufacturing (ICIEAM), 2016, pp. 1-4.
[25] I. Jaziri, L. Chaarabi, and K. Jelassi, "A remote DC motor control using Embedded Linux and FPGA," in 2015 7th International Conference on Modelling, Identification and Control (ICMIC), 2015, no. Icmic, pp. 1-5.

[26] B. Lobov, A. Mikitinskiy, and P. Kolpachshan, "The control of dosing pumps by modern electric drive," in 2016 2nd International Conference on Industrial Engineering, Applications and Manufacturing (ICIEAM), 2016, pp. 1-4.

[27] M. Payak and S. R. Kumbhar, "FPGA based PWM control of Induction motor drive and its parameter estimation," in 2015 International Conference on Applied and Theoretical Computing and Communication Technology (iCATccT), 2015, pp. 631-635.

[28] R. Waswani, A. Pawar, M. Deore, and R. Patel, "Induction motor fault detection, protection and speed control using arduino," in 2017 International Conference on Innovations in Information, Embedded and Communication Systems (ICIIECS), 2017, vol. 2018-Janua, pp. $1-5$.

[29] D. B. Durocher, M. R. Hussey, L. Rizzi, and D. Belzner, "Application of next-generation motor management relays to improve system reliability in process industries," in 2018 IEEEIAS/PCA Cement Industry Conference (IAS/PCA), 2018, pp. 1-9.

[30] H. H. Al-Leythi, Z. A. Mohammed, D. Hummes, G. A. Hussain, C. Caironi, and B. Fruth, "Motor Watch - Motor Fault Signature Analysis," in 2018 International Conference on Computing Sciences and Engineering (ICCSE), 2018, no. Im, pp. 1-5. 